\title{
Brioflora de duas florestas de terra firme na Área de Proteção Ambiental do Lago de Tucuruí, PA, Brasil ${ }^{1}$
}

\author{
Eline Tainá Garcia ${ }^{2,4}$, Anna Luiza Ilkiu-Borges² e Ana Cláudia Caldeira Tavares-Martins ${ }^{3}$
}

Recebido: 14.03.2013; aceito: 24.04.2014

\begin{abstract}
Bryoflora of two terra-firme forests in the Área de Proteção Ambiental do Lago de Tucuruí, Pará State, Brazil). The aim of this study was to investigate the richness of bryophytes (Bryophyta and Marchantiophyta) in two Wildlife Protection Areas at the Environmental Protection Area of Tucuruí Lake and to compare these results with the records of other mainland areas in the state of Pará. The sampling effort by area was of 200 botanical samples. In total, 90 species, 61 liverworts, and 29 mosses were registered, which represent $25 \%$ of the bryoflora of Pará State. Cololejeunea sicaefolia (Gottsche) Pócs \& Bernecker and Cololejeunea planissima (Mitt.) Abeyw. are new records for the Brazilian Amazon and Americas, respectively. The richness found, especially of taxa rarely or never before collected in the state, reinforces the importance of conserving these areas.
\end{abstract}

Keywords: Amazon, liverworts, mosses, richness

RESUMO - (Brioflora de duas florestas de terra firme na Área de Proteção Ambiental do Lago de Tucuruí, PA, Brasil). O objetivo deste trabalho foi investigar a riqueza da brioflora (Marchantiophyta e Bryophyta) de duas Zonas de Proteção da Vida Silvestre na Área de Proteção Ambiental Lago de Tucuruí, comparando os resultados encontrados com os de outras áreas de terra firme no Estado do Pará. O esforço amostral por área coletada foi de 200 amostras botânicas. No total, foram registradas 90 espécies, 29 musgos e 61 hepáticas, o que representa $25 \%$ da brioflora do Estado do Pará. Cololejeunea sicaefolia (Gottsche) Pócs \& Bernecker e Cololejeunea planissima (Mitt.) Abeyw. são novas citações para a Amazônia brasileira e para as Américas, respectivamente. A riqueza encontrada, principalmente de táxons pouco ou nunca antes coletados no Estado, reforça a importância da conservação dessas áreas.

Palavras-chave: Amazônia, hepáticas, musgos, riqueza

\section{Introdução}

As briófitas apresentam elevada riqueza e diversidade nos trópicos, o que provavelmente resulta da diversidade beta existente nessa região (Shaw et al. 2011). A brioflora da região neotropical é de aproximadamente 4.000 espécies (Gradstein \& Raeymaekers 2000). No Neotrópico são reconhecidas 10 fitoregiões, que abrigam centros de diversidade e endemismo para o grupo, dentre as quais estão a Amazônia e a Costa Atlântica do Brasil (Gradstein et al. 2001).

A Amazônia é um importante centro de endemismo para hepáticas, com cinco gêneros, sendo um endêmico do Brasil, além disso, abriga a segunda maior diversidade de Marchantiophyta do país. Na Amazônia brasileira registra-se a ocorrência de 571 espécies de briófitas (Gradstein et al. 2001, Gradstein \& Costa 2003, Costa 2014). O conhecimento da brioflora desse bioma ainda é limitado por alguns fatores como, a dificuldade de acesso às localidades mais afastadas dos grandes centros urbanos e pelo estudo parcial da flora pelos trabalhos, que englobam apenas musgos ou hepáticas, quadro relatado por Gradstein (1995), como sendo comum em inventários realizados em florestas tropicais. Os habitats de florestas tropicais estão sobre intensa ameaça em consequência de alterações ambientais, sejam elas de ordem natural e/ou antrópica e por isso estudos nessas áreas devem ser priorizados.

1. Parte da Dissertação de Mestrado da primeira Autora

2. Museu Paraense Emílio Goeldi, Coordenação de Botânica, Laboratório de Briologia. Av. Perimetral, 1901, Terra Firme, 66077-530 Belém, PA, Brasil

3. Universidade do Estado do Pará, Departamento de Ciências Naturais, Programa de Pós-Graduação em Ciências Ambientais, travessa Enéas Pinheiro, 2626, Marco, 66113-200 Belém, Pará, Brasil

4. Autor para correspondência: elinetgarcia@gmail.com 
A Amazônia brasileira é formada por aproximadamente $90 \%$ de florestas de terra firme (Pires 1973). O ambiente caracterizado por esse tipo de vegetação tem sido apontado como o mais rico em relação à brioflora, quando comparado aos demais estudados no Estado do Pará (Santos \& Lisboa 2003, Souza \& Lisboa 2005, 2006, Moraes \& Lisboa 2006, Lisboa \& Ilkiu-Borges 2007); exceções são os resultados encontrados por Lisboa \& Ilkiu-Borges (1996), Ilkiu-Borges \& Lisboa (2002a), Santos \& Lisboa (2008).

Apesar do avanço no estudo de briófitas no Estado do Pará, algumas regiões ainda são pouco documentadas quanto à brioflora, mesmo estando ameaçadas pela degradação ambiental resultante principalmente das atividades humanas. Uma dessas regiões é o sudeste paraense, que tem sofrido um processo acelerado de perda da vegetação nos últimos 20 anos e está completamente inserida em uma das áreas mais ameaçadas da Amazônia, denominada Arco do Desmatamento (Vieira et al. 2008).

O Reservatório da Usina Raul Garcia Llano ou Usina Hidrelétrica de Tucuruí (Reservatório de Tucuruí) localizado no sudeste do Estado do Pará foi formado em 1984 e submergiu uma grande área de vegetação (CMB 1999, 2002). Territórios de sete municípios foram inundados, originando ilhas de vegetação, fragmentos da floresta original que consistiam nas maiores elevações da região. A perda da vegetação não se limitou a área inundada pelo Reservatório de Tucuruí, mas também pela retirada de madeira às margens do mesmo, por moradores e pessoas que se deslocaram para a região atraídas pelas oportunidades de emprego (Fearnside 2001). A construção de reservatórios é citada por Hallingbäck \& Hodgetts (2000) como uma das ameaças à brioflora. Todavia, em função do potencial da bacia amazônica para a geração de energia, esses projetos são frequentes nessa região.

Os estudos de Ilkiu-Borges et al. (2004) e Tavares (2004) enfocaram as briófitas na região do Reservatório de Tucuruí. O primeiro inventariou musgos e hepáticas em um banco de germoplasma (Ilha de Germoplasma) e o segundo foi realizado em uma Base de Apoio (Base 5) do projeto da Usina e oito ilhas formadas com a inundação do Reservatório e tratou apenas as Lejeuneaceae. As diferenças ambientais entre a Ilha de Germoplasma e as áreas estudadas por Tavares (2004) (e.g. pequena área de vegetação artificial e remanescentes de floresta nativa) refletem-se nas riquezas de espécies identificadas por Ilkiu-Borges et al. (2004) e Tavares (2004), 25 e 44 espécies, respectivamente. Além disso, essas riquezas contrastam com a abrangência taxonômica dos trabalhos (e.g. táxons de musgos e hepáticas e o outro, uma família).

Os resultados supracitados indicaram a necessidade de estudos mais abrangentes sobre a riqueza de briófitas na região do Reservatório de Tucuruí. Assim, o objetivo deste trabalho foi investigar a riqueza da brioflora (Marchantiophyta e Bryophyta) de duas Zonas de Proteção da Vida Silvestre na Área de Proteção Ambiental Lago de Tucuruí, comparando os resultados encontrados com o de outras áreas de terra firme no estado do Pará.

\section{Material e métodos}

Área de estudo - O Reservatório da Usina Hidrelétrica de Tucuruí está localizado na região sudeste do Estado do Pará. As Bases 3 e 4, usadas durante a execução do projeto da usina como zonas de soltura para os animais resgatados das áreas inundadas, tornaram-se as Zonas de Proteção da Vida Silvestre E (ZPVS E) e D (ZPVS D), respectivamente (figura 1). Estão inseridas na Área de Proteção Ambiental Lago de Tucuruí criada pela Secretaria de Estado de Meio Ambiente - SEMA conforme Lei $\mathrm{N}^{\mathrm{o}} 6.451$ de 08/04/2002 (SEMA 2012).

A região apresenta um clima com duas estações bem definidas: um período chuvoso de dezembro a maio (inverno) e outro período seco de junho a novembro (verão), e um período de estiagem em agosto e setembro (Fisch et al. 1990). A temperatura tem pouca variação durante o ano inteiro, com médias mensais superiores a $24{ }^{\circ} \mathrm{C}$; a pluviosidade anual é superior a $2.500 \mathrm{~mm}$ (Sanches \& Fisch 2005); a vegetação da área é de Floresta Ombrófila, onde predomina floresta densa de terra firme com castanheiras e florestas abertas de terra firme com cipós e palmeiras (Leão et al. 2005, Henriques 2007).

As áreas de estudo localizam-se em margens opostas do Reservatório de Tucuruí. A ZPVS-E está localizada na margem esquerda, no município de Novo Repartimento, a 4²1'11,3"S e 49³7'12,8"W. A ZPVS-D está localizada na margem direita, no município de Goianésia do Pará, a $4^{\circ} 15^{\prime} 07,9^{\prime \prime} \mathrm{S}$ e 49³2'05,3"W. A vegetação em ambas as áreas é formada por florestas abertas de terra firme.

Amostragem e identificação dos táxons - O material botânico foi coletado em setembro de 2000 e buscou-se uniformizar a coleta em cada área, estabelecendo um padrão que consistiu em: 1) percorrer uma trilha no sentido margem-interior da floresta, descontando 50 metros da borda; 2) esforço amostral de 200 amostras em 
cada uma das ZPVS; cinco amostras não apresentaram material suficiente para identificação dos táxons e foram excluídas. As metodologias de coleta, armazenamento e herborização foram baseadas em Yano (1984a).

A identificação dos táxons seguiu as técnicas usuais para o grupo, com auxílio de literaturas especializadas e sendo alguns táxons confirmados por especialistas, quando necessário.

As classificações adotadas neste trabalho foram as de Goffinet et al. (2009), para Bryophyta e a de Crandall-Stotler et al. (2009), para Marchantiophyta. O material analisado foi incorporado ao Herbário João Murça Pires do Museu Paraense Emílio Goeldi (MG).

Análise dos dados - Os dados foram analisados quanto à riqueza, distribuição geográfica dos táxons e similaridade florística com florestas de terra firme do nordeste paraense. Na análise de riqueza, a mesma foi considerada como o número absoluto de espécies encontrado em cada área.

Os estimadores não paramétricos Jackknife 1 e Chao 2 (Colwell \& Coddington 1994) foram utilizados para prever os valores de riqueza esperados em cada uma das áreas. Para isso foram elaboradas duas matrizes (uma para cada área) com dados de presença/ausência submetidas à análise no programa EstimateS 8.2.0 (Colwell 2009). Os resultados gerados pelos estimadores foram comparados com a riqueza absoluta encontrada nas ZPVS através de um cálculo de proporção, a fim de obter o percentual amostrado em relação ao esperado (previsão dos estimadores).

Para verificar a suficiência da amostragem em cada uma das áreas foi construída uma matriz de presença e ausência das espécies em cada amostra, a fim de gerar uma curva cumulativa de espécies com intervalo de confiança de $95 \%$ através da função Mao Tau (Cowell et al. 2004). Para os cálculos das análises descritas anteriormente foi utilizado o programa EstimateS 8.2.0 (Colwell 2009).

A distribuição dos táxons foi determinada de acordo com informações contidas nas bases onlines da Lista de Espécies da Flora do Brasil (Bastos 2013, Bordin 2013, Camara 2013, Costa 2013a,b,c,d,e, Costa \& Bastos 2013, Costa \& Peralta 2013a,b,c,d,e, Peralta 2013), Banco de Dados Briófitas do Estado
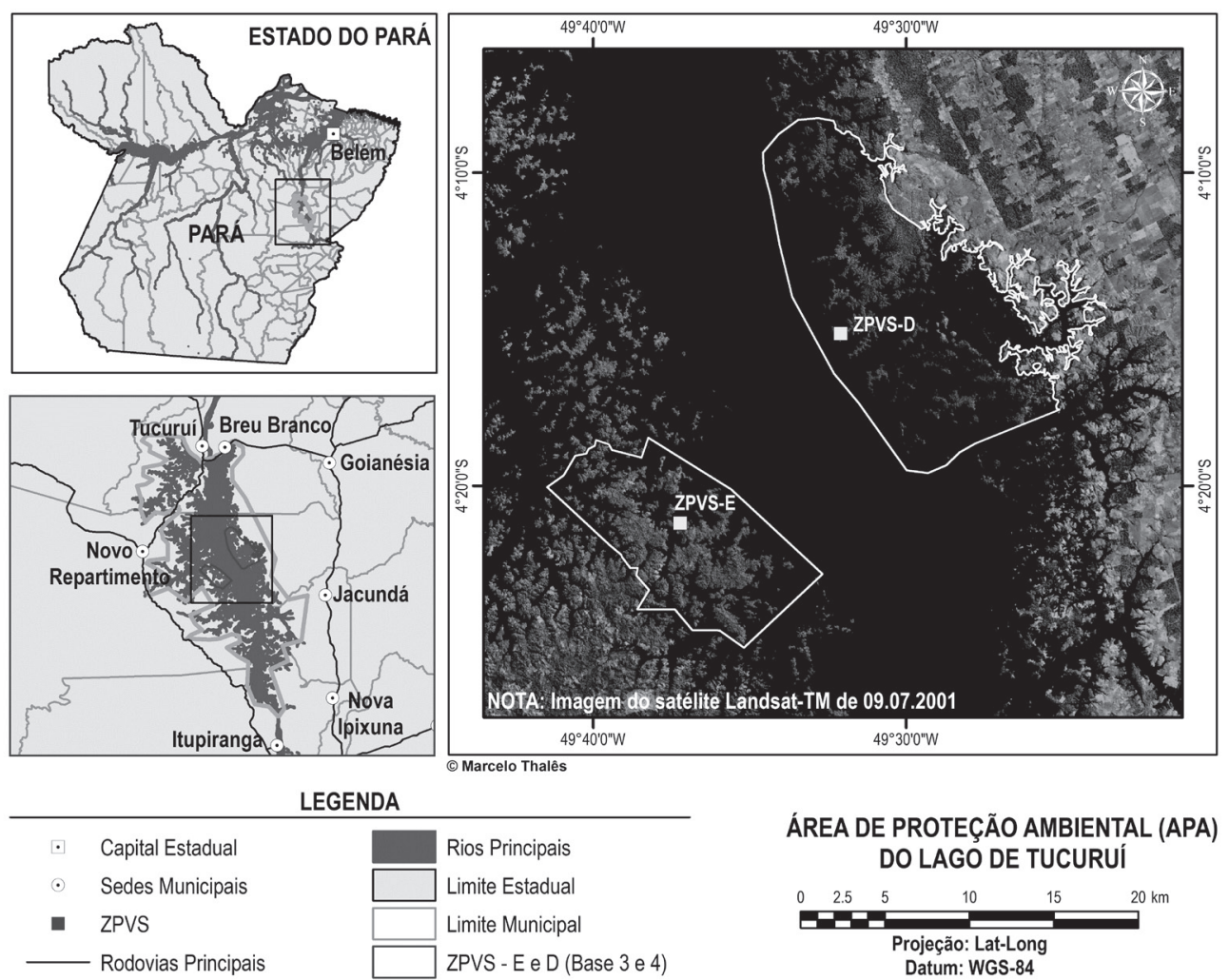

LEGENDA

Rios Principais

ÁREA DE PROTEÇÃO AMBIENTAL (APA) DO LAGO DE TUCURUI

Limite Estadual

Limite Municipal

ZPVS - E e D (Base 3 e 4)

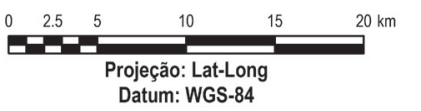

Figura 1. Localização das Zonas de Proteção da Vida Silvestre (ZPVS-E e D), Área de Proteção Ambiental Lago de Tucuruí, PA, Brasil.

Figure 1. Location of Wildlife Protection Areas (E and D) at the Tucuruí Lake Environmental Protection Area, Pará state, Brazil. 
do Rio de Janeiro (Costa et al. 2007) e nos trabalhos de Gradstein \& Costa (2003), Yano (2008, 2011a, 2011b), Gradstein \& Ilkiu-Borges (2009), Peralta \& Yano (2011) e Yano \& Peralta (2011). A distribuição está apresentada por região geográfica e a abreviação dos Estados Brasileiros está de acordo com o Instituto Brasileiro de Geografia e Estatística (IBGE).

A brioflora das duas áreas de estudo foi comparada com as de outras três florestas de terra firme no Estado do Pará, totalizando cinco áreas (amostras). Essas florestas já possuíam estudos sobre as floras de musgos e hepáticas, são elas: Floresta Nacional de Caxiuanã/ FLONA-Caxiuanã (Ilkiu-Borges et al. 2013); Reserva do Mocambo/RE-Mocambo (Lisboa \& Ilkiu-Borges 2007) e florestas de terra firme no município de Capitão Poço/F-TF-Capitão Poço (Tavares-Martins et al.2014).

Para análise da similaridade florística entre as briofloras das áreas, foi elaborada uma matriz de dados binários (presença $\times$ ausência) para 182 táxons, sendo considerados apenas táxons determinados em nível de espécie listados nos trabalhos (Lisboa \& Ilkiu-Borges 2007, Ilkiu-Borges et al. 2013 (Tavares-Martins et al. 2014). As espécies raras, que ocorreram em apenas uma amostra (área) foram excluídas, para aumentar a eficiência da análise. A matriz final consistiu de dados de 111 espécies de briófitas. A similaridade foi calculada através do coeficiente de Jaccard, o qual considera peso igual para todas as espécies, o que pode reduzir erros relacionados ao esforço amostral empregado em cada levantamento. Nesta análise foi utilizado o software MVSP 3.0 (Kovack 2011).

\section{Resultados e Discussão}

Foram analisadas 395 amostras botânicas, com registro de 1.488 ocorrências e 90 espécies (29 musgos e 61 hepáticas). As espécies inventariadas (90 spp.) estão distribuídas em 38 gêneros e 14 famílias, das quais nove pertencem à Bryophyta (musgos) e cinco à Marchantiophyta (hepáticas) (tabela 1). Na ZPVS-E foram registradas $78 \mathrm{spp}$. (28 musgos e 50 hepáticas) em 865 ocorrências e a na ZPVS-D, 67 spp. (20 musgos e 47 hepáticas) em 623 ocorrências. Incluindo os resultados deste estudo, a brioflora do Estado do Pará engloba 363 espécies (Yano 1981, 1984b, 1989, 1995, 2006, 2008, Lisboa \& Ilkiu-Borges 1995, 2007, Lisboa \& Santos 2005a, b, Souza \& Lisboa 2005, 2006, Moraes \& Lisboa 2006, Costa 2012). As briófitas das duas áreas estudadas representam aproximadamente $25 \%$ da brioflora do Estado.

Ao serem comparados, os valores de riqueza previstos pelos estimadores com os encontrados, observou-se que mais de $80 \%$ das espécies estimadas para as áreas foram amostradas. Esse resultado somado aos das curvas de cumulação, que embora não tenham estabilizado, mostraram uma tendência a isso (figuras 2 e 3), sugerindo que as amostragens foram suficientes para representar a brioflora das ZPVS, uma vez que, não é possível saber o esforço de coleta necessário para esgotar uma área (Vanzolini 1992) e ainda, que em florestas tropicais as curvas não estabilizam (Schilling \& Batista 2008).

$\mathrm{Na}$ riqueza inventariada observa-se que, embora Marchantiophyta esteja representada por um menor número de famílias (cinco), esta concentrou aproximadamente $68 \%$ das espécies e uma maior riqueza em relação aos musgos em ambas as áreas. Somente Lejeuneaceae representou 58\% (52 spp.) das espécies listadas neste estudo (90 spp.) e nas espécies compartilhadas entre as áreas (55 spp.), a maioria (33 spp.) também pertence a esta família. De acordo com Gradstein et al. (2001), 70\% das hepáticas de florestas tropicais são Lejeuneaceae. Os resultados de estudos realizados com musgos e hepáticas na Amazônia têm ratificado essa afirmação (Lisboa \& Ilkiu-Borges 2007, Alvarenga \& Lisboa 2009).

Oito padrões fitogeográficos foram identificados, com maior riqueza de táxons apresentando padrão Neotropical (44 spp.; 49\%), seguido do Pantropical (18 spp.; 20\%) e América Tropical e Subtropical (14 spp.; 16\%). Seis espécies apresentam padrão Afroamericano (7\%), três distribuem-se na América do Sul (3\%) e três espécies apresentam padrão Amplo (3\%). Uma espécie apresenta padrão Americano (1\%) e uma é restrita a Amazônia (1\%).

Uma maior riqueza de táxons com padrão Neotropical também foi reportada por outros estudos realizados em florestas tropicais brasileiras (IlkiuBorges \& Lisboa 2002a, Tavares 2004, Santos \& Costa 2010). As briofloras das áreas de estudo confirmam para estas florestas de terra firme na Amazônia oriental o sugerido por Schuster (1983) sobre a maior ocorrência de táxons com amplos padrões de distribuição em florestas de terras baixas, o que também já foi observado por Santos et al. (2011) em habitats de restinga e florestas ombrófilas de terras baixas na Mata Atlântica.

Na brioflora das ZPVS-E e D, aproximadamente $62 \%$ das espécies de briófitas (56 spp.) possuem ampla distribuição no território brasileiro, ocorrendo em todas as regiões do país (figura 4). Seis espécies têm registros de ocorrência somente na região Norte. As espécies Prionolejeunea muricatoserrulata(Spruce) 


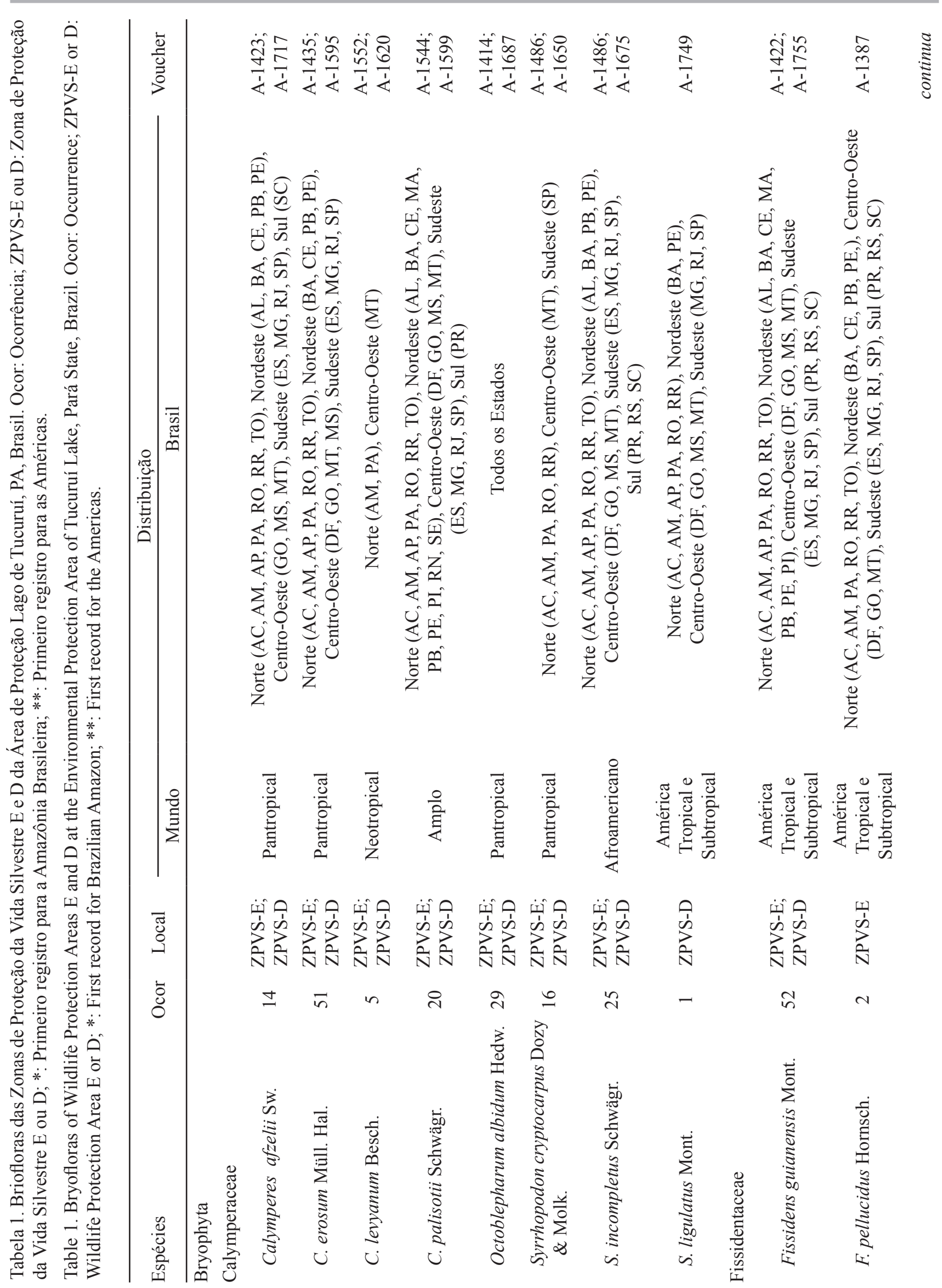




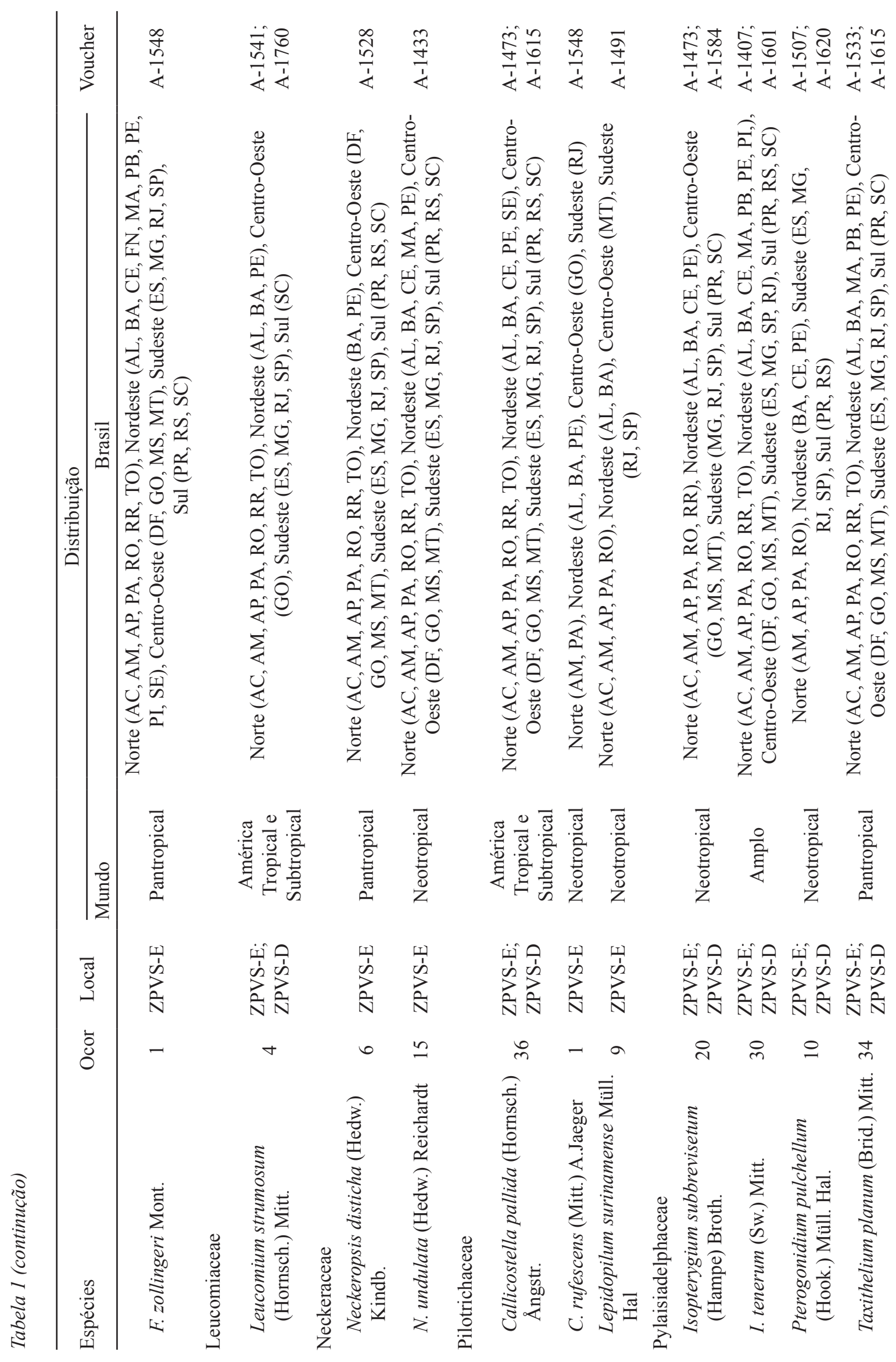




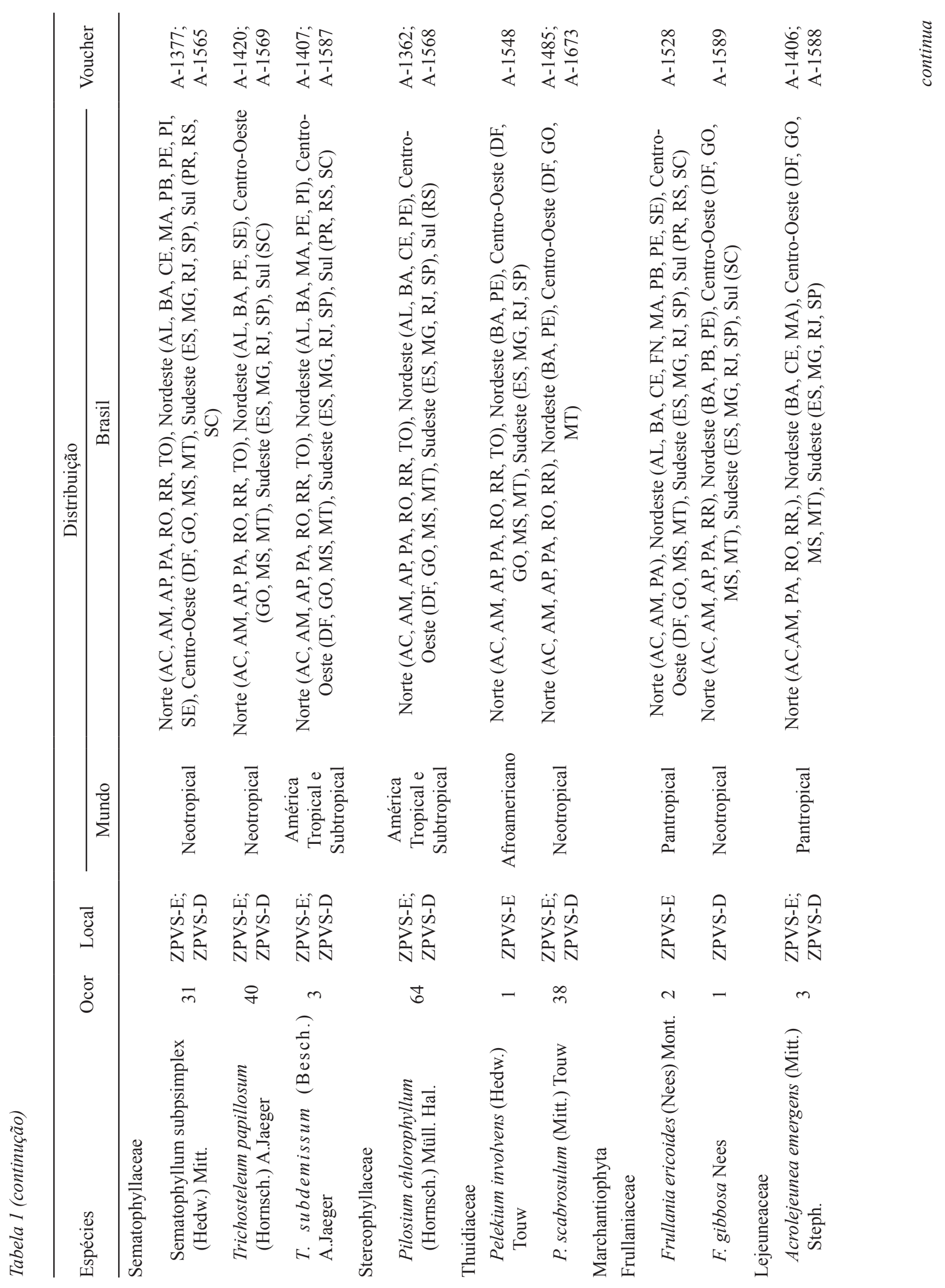




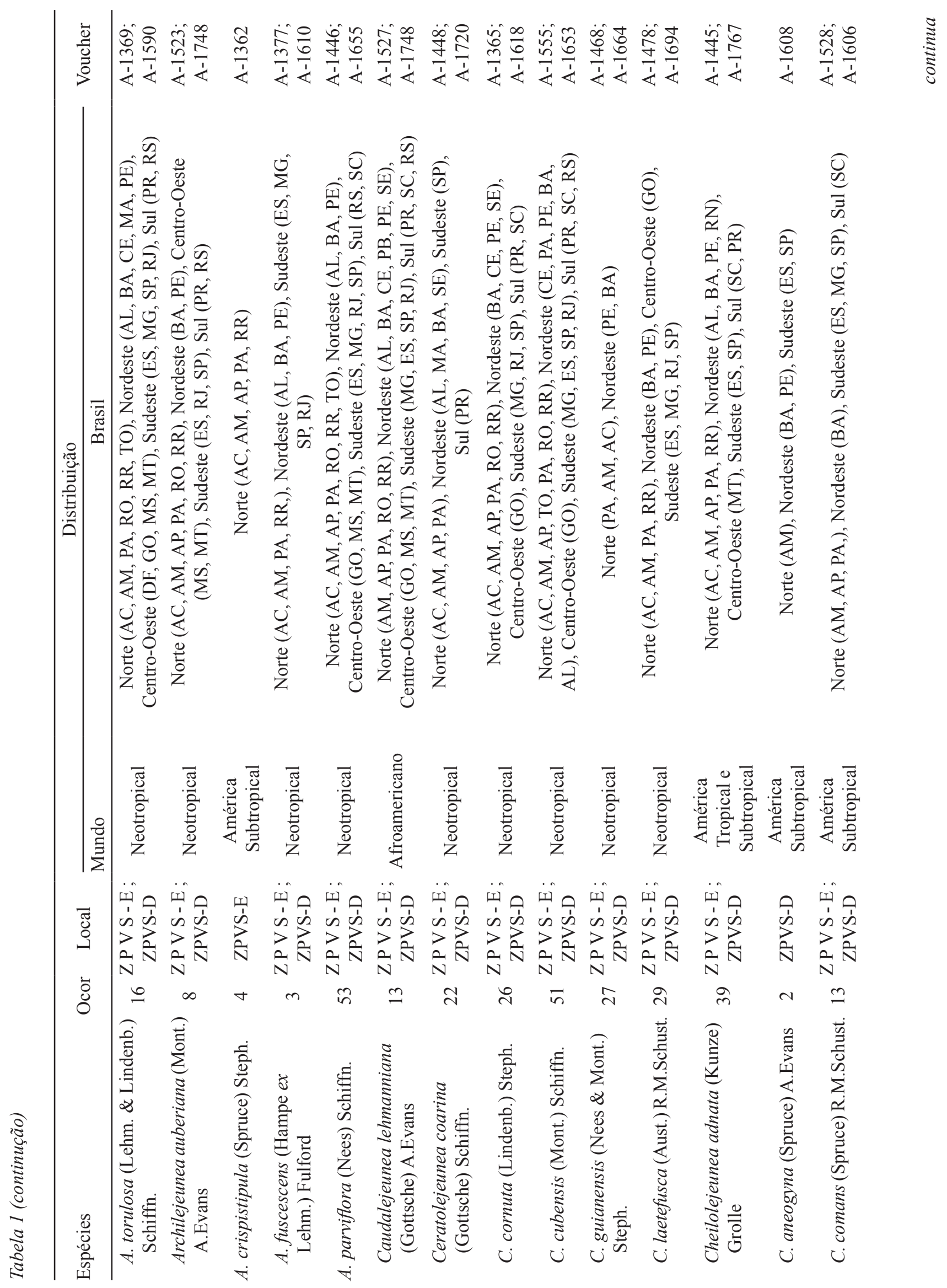




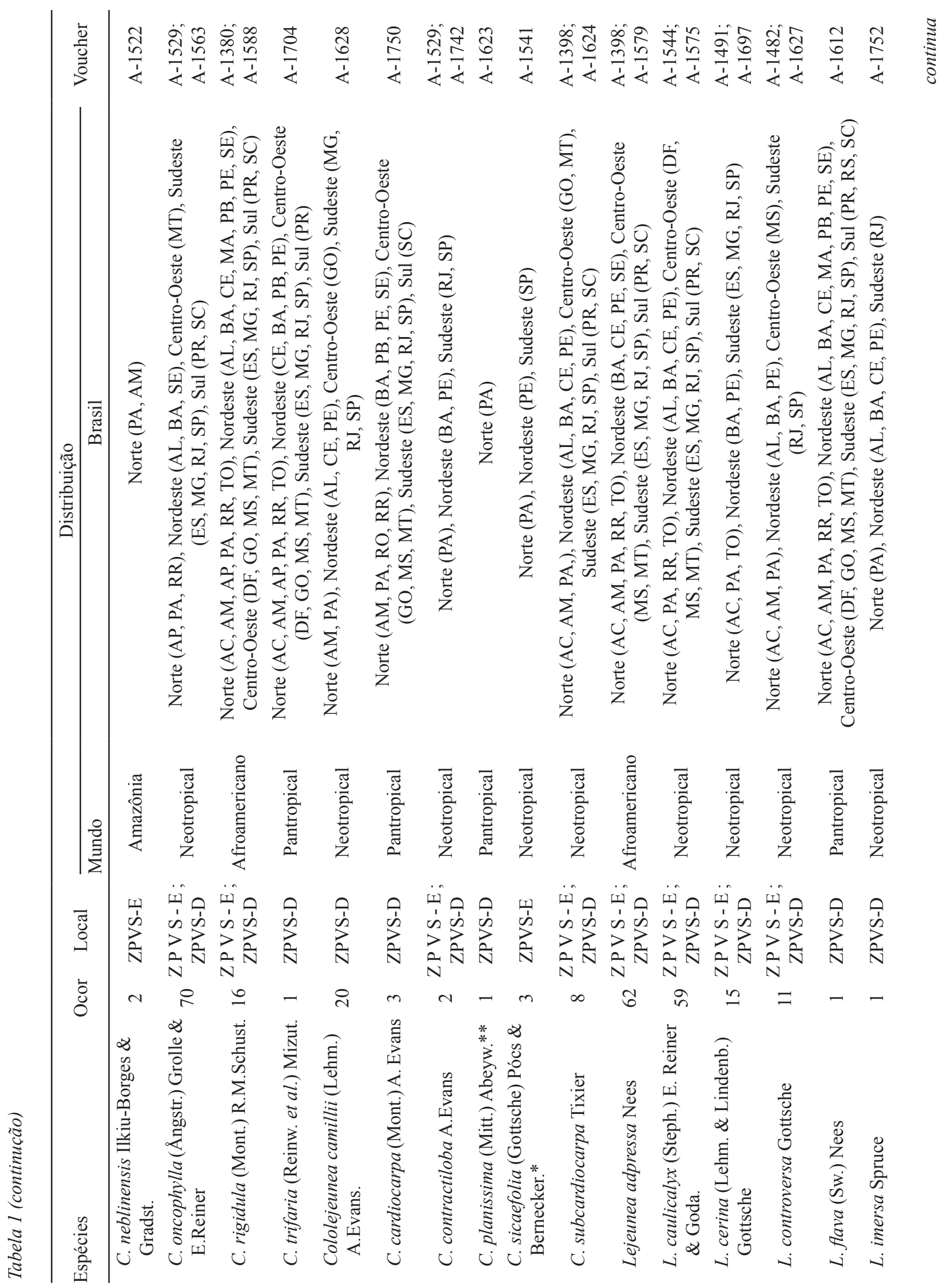




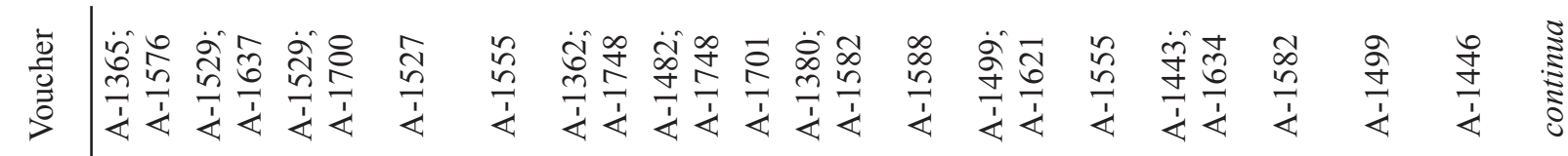

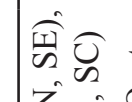

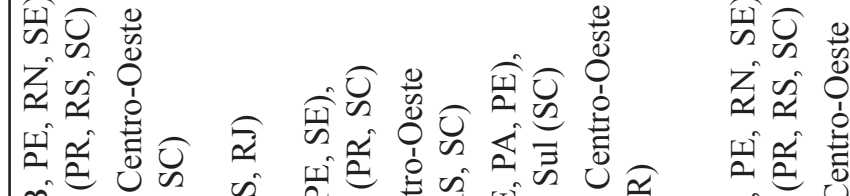

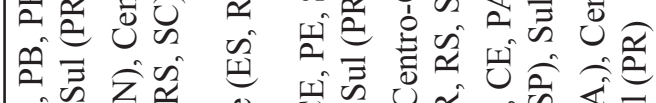

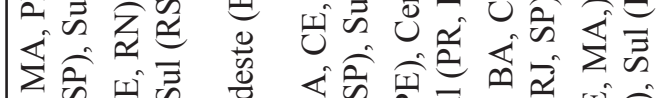

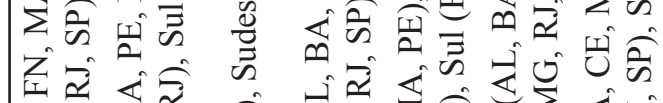

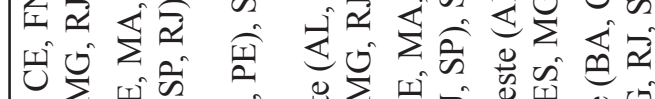

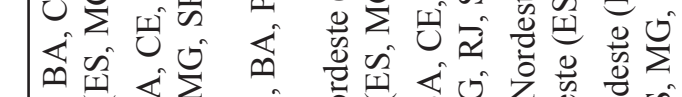

$\overline{7}$

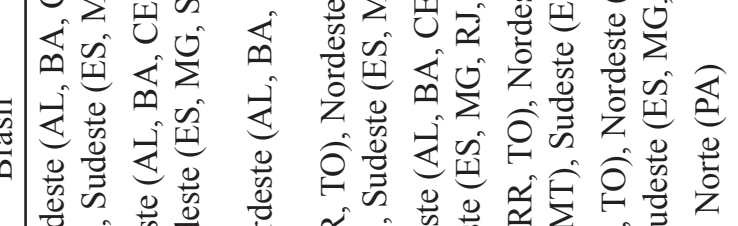

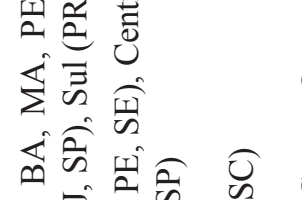

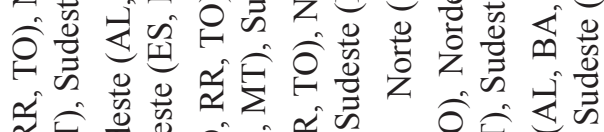

जी ती जी जी

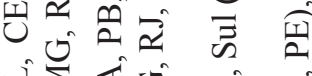

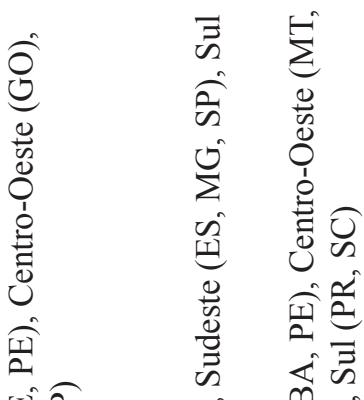

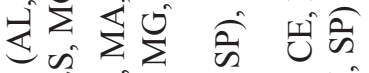

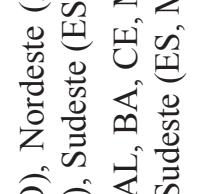

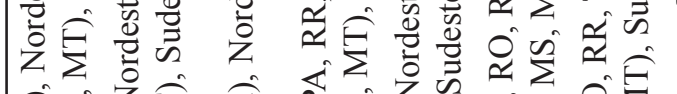

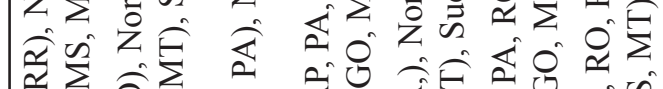

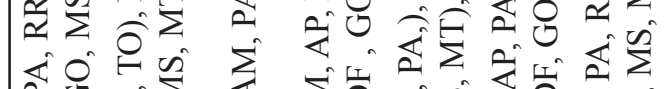

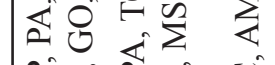

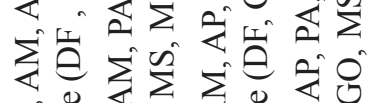

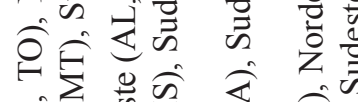

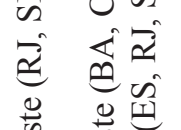

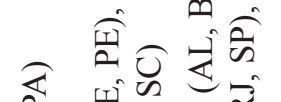

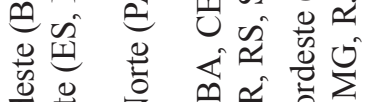

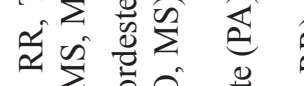

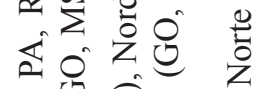

论

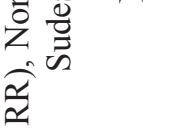

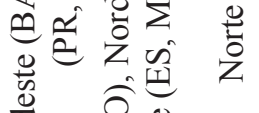

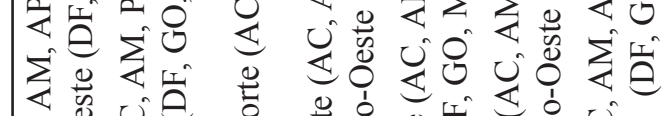

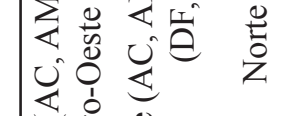

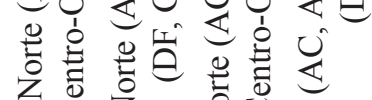

$\sum e_{0}$

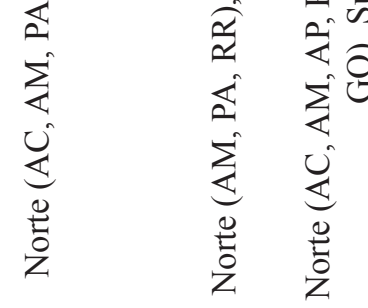

Z

这

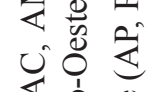

落

\begin{tabular}{ll} 
& \multirow{1}{*}{0} \\
0 & 0 \\
0 & 0 \\
0 & 0 \\
0 & 0 \\
0 & 0
\end{tabular}

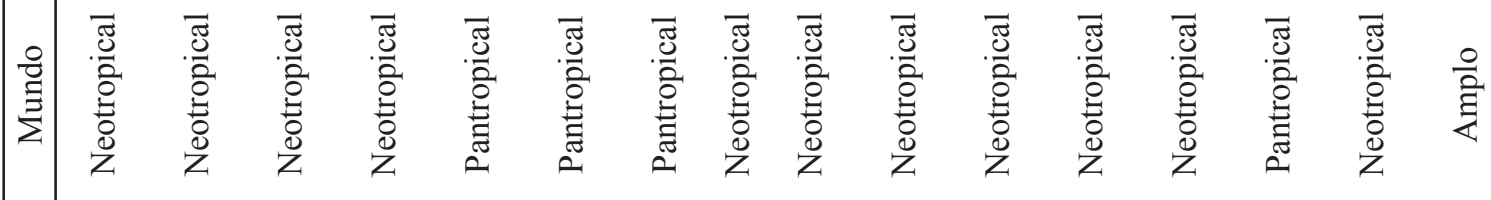

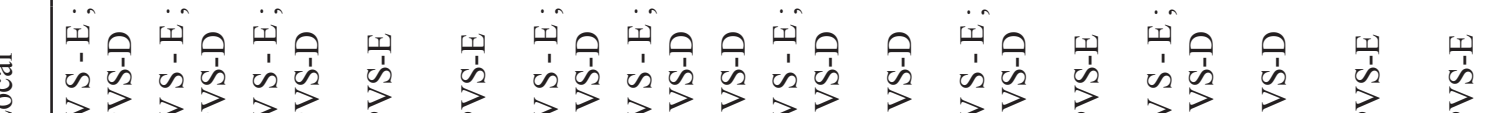

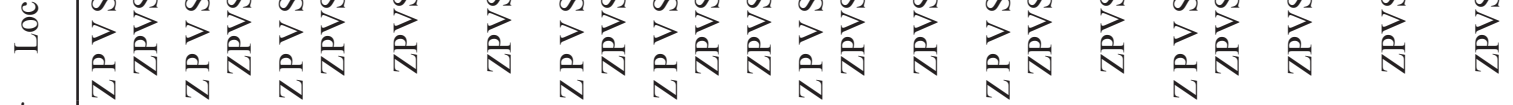

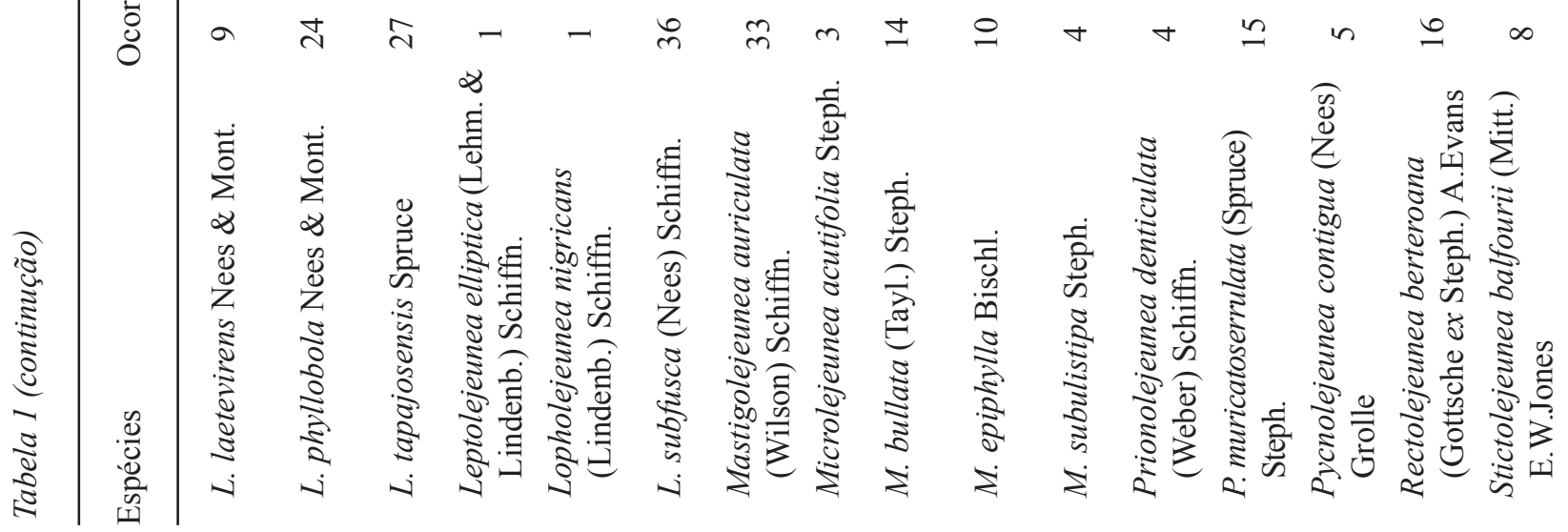




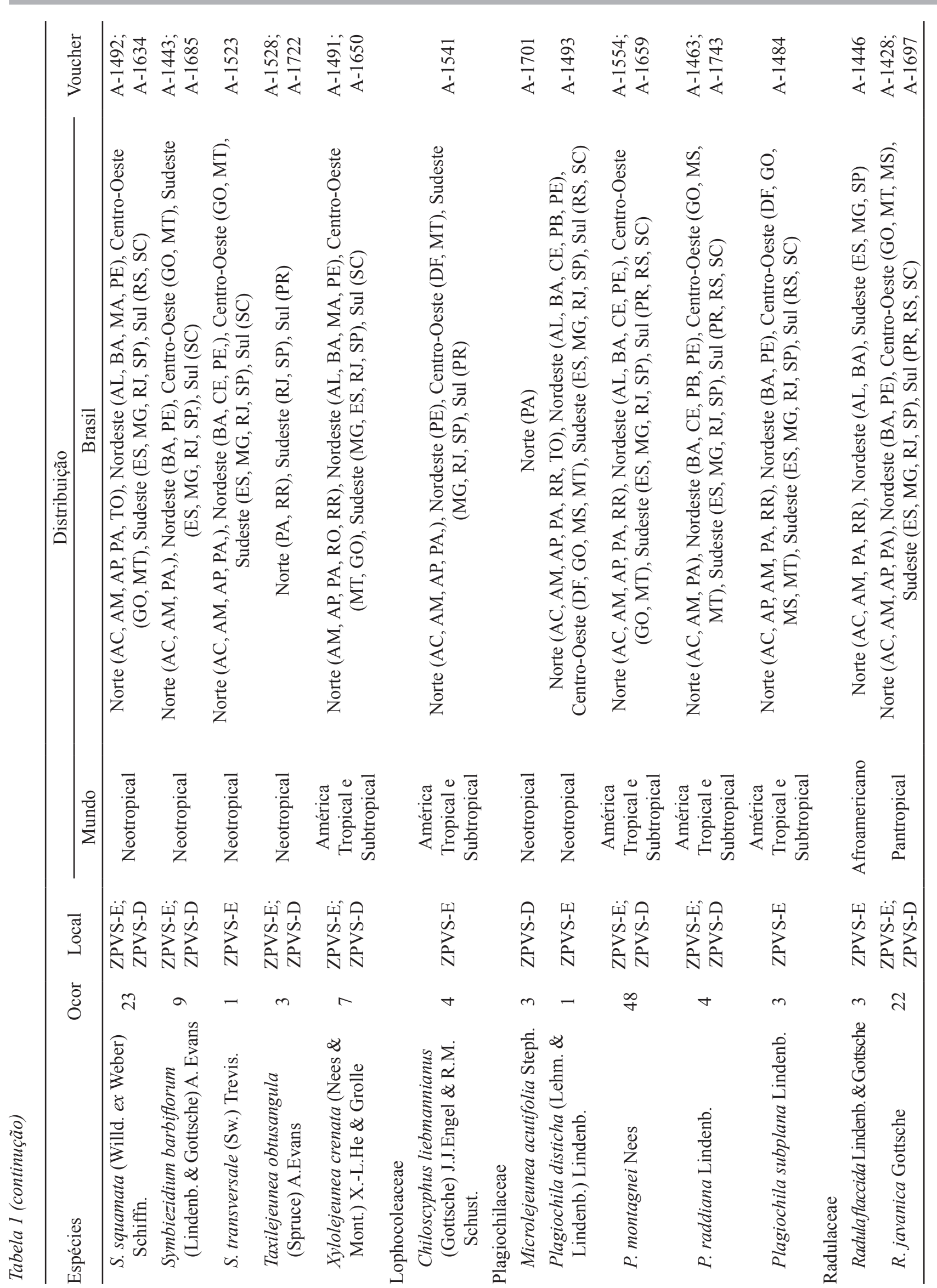


Steph. e Microlejeunea acutifolia Steph.ocorrem apenas no Estado do Pará.

A espécie Stictolejeunea balfourii (Mitt.) E.W.Jones é citada apenas para os Estados do Acre e Pará, é uma espécie de ampla distribuição que tem se dispersado a curtas distâncias ao longo dos anos (Gradstein 1995) e, provavelmente, é pouco coletada devido ao seu hábito reofítico (Gradstein \& IlkiuBorges 2009). No Brasil, Cheilolejeunea neblinensis Ilkiu-Borges \& Gradst., também é conhecida para os Estados do Maranhão (L.P.C. Macedo, dados não publicados), Amazonas (Bastos 2013) e Pará (IlkiuBorges et al. 2013).

Nas áreas de estudo, destacam-se os registros de Cololejeunea sicaefolia (Gottsche) Pócs \& Bernecker na ZPVS-E e de Cololejeunea planissima (Mitt.) Abeyw. na ZPVS-D, que até este trabalho não haviam sido citadas para o Estado do Pará. No Brasil, Cololejeunea sicaefolia, anteriormente reportada apenas para os Estados de Pernambuco e São Paulo é citada pela primeira vez para a Amazônia brasileira. Cololejeunea planissima é uma espécie bem distribuída na Ásia e no Sudeste da África e sua ocorrência é reportada pela primeira vez nas Américas, neste trabalho.

Quando avaliada a similaridade florística entre florestas de terra firme estudadas no Estado do Pará, as florestas do nordeste (RE-Mocambo, FLONACaxiuanã e F-TF-Capitão Poço) e as do sudeste do Estado (ZPVS-E e D) apresentaram baixa similaridade (33\% de similaridade florística), formando dois grupos

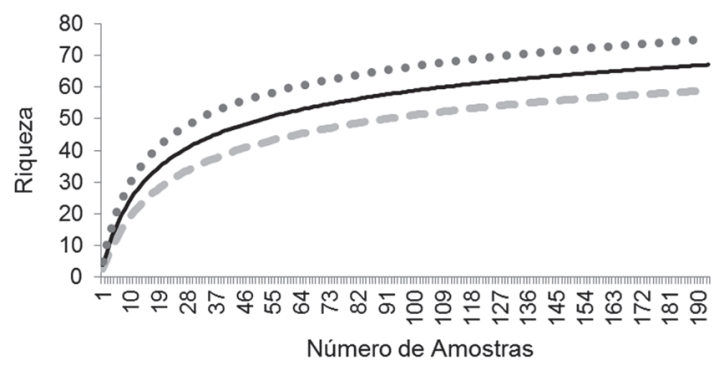

Figura 2. Curva de acumulação de espécies em relação ao número de amostras (Mao Tau), Zona de Proteção da Vida Silvestre-E, Área de Proteção Ambiental Lago de Tucuruí, PA, Brasil. - - Sobs 95\% limite inferior; - Sobs (Mao Tau); … Sobs 95\% limite superior.

Figure 2. Accumulation curve of species in relation to the number of samples (Mao Tau), Wildlife Protection Areas-E, Área de Proteção Ambiental Lago de Tucuruí, Pará State, Brazil. - - Sobs 95\% Lower Bound; - Sobs (Mao Tau); .... Sobs 95\% Upper Bound distintos (figura 5). Essa diferença na composição é, provavelmente, reflexo dos táxons ocorrentes nas áreas de estudo que foram pouco coletados ou nunca coletados (novos registros) em outros trabalhos. As espécies compartilhadas entre todas as áreas são principalmente, táxons de grande amplitude ecológica e muito frequentes em florestas de planície e também na floresta atlântica, tais como, Archilejeunea parviflora (Nees) Schiffn., Ceratolejeunea cornuta (Lindenb.) Steph., Cheilolejeunea rigidula (Mont.) R.M.Schust., Calymperes erosum Müll. Hal., Sematophyllum subsimplex (Hedw.) Mitt. e Syrrhopodon incompletus Schwägr.

A flora da RE-Mocambo diferenciou-se entre as florestas do nordeste paraense. Esta área apresenta um elevado grau de umidade e floresta densa, com pouca luz (Pires 1976, Pires \& Prance 1977, Pires \& Salomão 2007) o que pode explicar a distinção entre as demais áreas. As F-TF-Capitão Poço e a FLONA-Caxiuanã foram bastante similares $(0,51)$. Algumas espécies ocorreram apenas nessas duas áreas, em floresta maduras em bom estado de conservação ou de elevado estágio de sucessão, tais como Haplolejeunea cucullata (Stephani) Grolle, Micropterygium leiophyllum Spruce e Pictolejeunea picta (Gottsche ex. Steph.) Grolle.

As florestas do sudeste do Estado apresentaram maior valor de similaridade entre si $(0,70)$ nas amostras (áreas) analisadas e compartilharam 55 espécies, sendo Calymperes levyanum Besch., Cheilolejeunea comans (Spruce) R.M.Schust. e Microlejeunea subulistipa

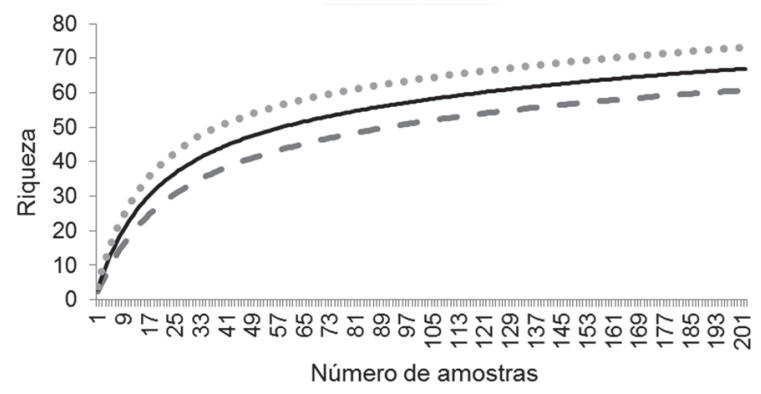

Figura 3. Curva de acumulação de espécies em relação ao número de amostras (Mao Tau), Zona de Proteção da Vida Silvestre-D, Área de Proteção Ambiental Lago de Tucuruí, PA, Brasil. - - Sobs 95\% limite inferior; - Sobs (Mao Tau); .... Sobs 95\% limite superior.

Figure 3. Accumulation curve of species in relation to the number of samples (Mao Tau), Wildlife Protection Areas-D, Área de Proteção Ambiental Lago de Tucuruí, Pará State, Brazil. - - Sobs 95\% Lower Bound; - Sobs (Mao Tau); .... Sobs 95\% Upper Bound 
Steph., exemplos de espécies que foram pouco frequentes nas áreas de estudo e que também são pouco coletadas no Estado, mas já foram reportadas por outros estudos no Estado (Tavares et al. 2006, Moraes \& Lisboa 2009, Brito \& Ilkiu-Borges 2013).

A singularidade das florestas de terra firme do sudeste paraense também é amparada pela ocorrência de táxons registrados apenas nessas áreas, tais como: Cololejeunea sicaefolia e C. planissima. Exceto Cheilolejeunea neblinensis Ilkiu-Borges \& Gradst. que possui distribuição restrita à Amazônia, os demais táxons apresentam distribuição igual ou mais ampla que a neotropical e $62 \%$ das espécies possuem ampla distribuição nas regiões brasileiras.

O compartilhamento de espécies com florestas maduras e bem conservadas reforçam a necessidade de conservação das ZPVS-E e D, principalmente pela

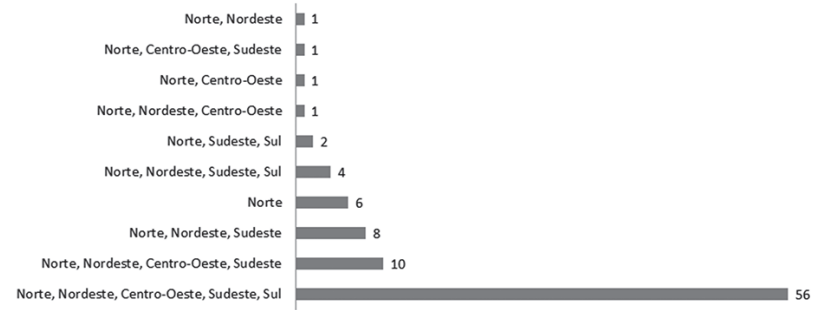

Figura 4. Riqueza de espécies encontradas nas ZPVS (E, D), Área de Proteção Ambiental Lago de Tucuruí, PA, Brasil e distribuição por região brasileira.

Figure 4. Richness of species found in the Wildlife Protection Areas (E, D), Área de Proteção Ambiental Lago de Tucuruí, Pará State, Brazil and its distribution by Brazilian region.

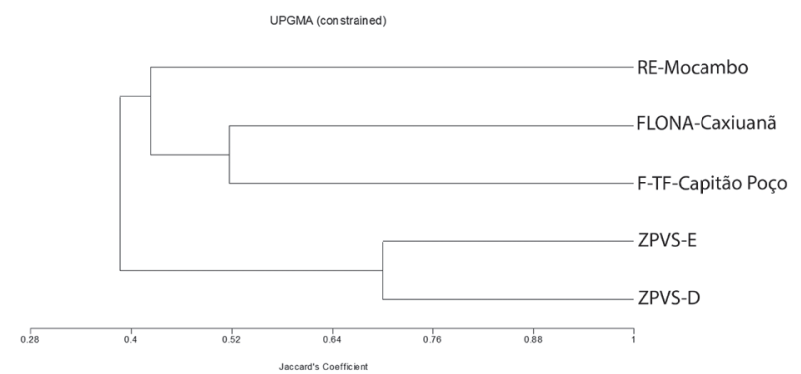

Figura 5. Similaridade florística entre Florestas de Terra Firme no Estado do Pará Brasil. RE-Mocambo: Reserva Mocambo, FLONACaxiuanã: Floresta Nacional de Caxiuanã, F-TF-Capitão Poço: Florestas de Terra Firme de Capitão Poço, ZPVS-E: Zona de Proteção da Vida Silvestre E, ZPVS-D: Zona de Proteção da Vida Silvestre D.

Figure 5. Floristic similarity between terra firme forests in the Pará State, Brazil. RE-Mocambo: Reserve Mocambo, FLONACaxiuanã: Caxiuanã National Forest, F-TF-Capitão Poço: terra firme forests at the municipality of Capitão Poço, ZPVS-E: Wildlife Protection Area E, ZPVS-D: Wildlife Protection Area D. presença de espécies pouco registradas em outros inventários na Amazônia. Além disso, essas áreas são importantes para a conservação da brioflora, visto que englobam $25 \%$ da brioflora do Estado. No Estado do Pará, nos últimos dez anos, tem aumentado os estudos taxonômicos que incluem tanto a flora de musgos quanto a de hepáticas. Estes, constantemente acresceram novos registros para o Estado, país e para a ciência, principalmente de espécies de hepáticas, a exemplo dos trabalhos de Ilkiu-Borges \& Lisboa (2002b, c, 2004), Alvarenga et al. (2007), Moraes \& Lisboa (2009), Brito \& Ilkiu-Borges (2012), Moura et al. (2012).

Os dados atuais demonstram que a realização de estudos que enfoquem as floras conjuntas (musgos e hepáticas) é importante para o conhecimento da riqueza local. E assim, levantamentos florísticos em áreas com a brioflora ainda desconhecida ou que tiveram apenas a flora de musgos tratada são necessários, esperando-se um incremento da brioflora do Estado, principalmente com espécies de hepáticas, pois, como reporta Richards (1984), a riqueza de hepáticas é maior que a de musgos em florestas tropicais de planície.

\section{Agradecimentos}

À Coordenação de Aperfeiçoamento de Pessoal de Nível Superior, pela concessão da Bolsa de Mestrado à primeira Autora; às M.Sc. Eliete da Silva Brito, Dra. Eryka de Nazaré Rezende Moraes e Dra. Rita de Cássia Pereira dos Santos, pela confirmação de espécies de musgo.

\section{Literatura citada}

Alvarenga, L.D.P. \& Lisboa, R.C.L. 2009. Contribuição para o conhecimento da taxonomia, ecologia e fitogeografia de Briófitas da Amazônia Oriental. Acta Amazonica 39: 495-504.

Alvarenga, L.D.P., Lisboa, R.C.L. \& Tavares, A.C.C. 2007. Novas referências de hepáticas (Marchantiophyta) da Floresta Nacional de Caxiuanã para o Estado do Pará, Brasil. Acta Botanica Brasilica 21: 649-656.

Bastos, C.J.P. 2013. Cheilolejeunea. In: Lista de Espécies da Flora do Brasil. Jardim Botânico do Rio de Janeiro. Disponível em http://floradobrasil.jbrj.gov.br/jabot/ floradobrasil/FB97423 (acesso em 16-XI-2013).

Bordin, J. 2013. Fissidentaceae. In: Lista de Espécies da Flora do Brasil. Jardim Botânico do Rio de Janeiro. Disponível em http://floradobrasil.jbrj.gov.br/jabot/ floradobrasil/FB96294 (acesso em 16-XI-2013). 
Brito, E.S. \& Ilkiu-Borges, A.L. 2012. Primeiro registro de Cololejeuna panamensis G.Dauphin \& Pócs (Lejeuneaceae) para a América do Sul. Rodriguésia 63: 1-3.

Brito, E.S. \& Ilkiu-Borges, A.L. 2013. Bryoflora of the municipalities of Soure and Cachoeira do Arari, on Marajó Island, in the state of Pará, Brazil. Acta Botanica Brasílica 27: 124-141.

Camara, P.E.A.S. 2013. Sematophyllaceae. In: Lista de Espécies da Flora do Brasil. Jardim Botânico do Rio de Janeiro. Disponível em http://floradobrasil.jbrj.gov.br/ jabot/floradobrasil/FB96994 (acesso em 16-XI-2013).

CMB. 1999. Comissão Mundial de Barragens - Estudos de Caso, Usina Hidrelétrica de Tucuruí. Relatório de escopo. Disponível em http://www.dams.org/ docs/kBase/studies/drafts/brscp_pt.pdf (acesso em 25-VII-2010).

CMB. 2002. Comissão Mundial de Barragens - Estudos de Caso, Usina Hidrelétrica de Tucuruí (Brasil). Disponível em https://www.lima.coppe.ufrj.br/files/projetos/ema/ tucurui_rel_final.pdf (acesso em 01-III-2012).

Colwell, R.K. 2009. EstimateS: Statistical estimation of species richness and shared species from samples [Online]. Disponível em http://viceroy.eeb.uconn.edu/ EstimateS (acesso em 09-XII-2011).

Colwell, R.K. \& Coddington, J.A. 1994. Estimating terrestrial biodiversity through extrapolation. Philosophical Transactions. Royal Society London (Ser. B) 345: 101-118.

Colwell, R.K., Mao, C.X. \& Chang, J. 2004. Interpolating, extrapolating, and comparing incidence-based species accumulation curves. Ecology 85: 2717-2727.

Costa, D.P. 2012. Briófitas. In: Lista de Espécies da Flora do Brasil. Jardim Botânico do Rio de Janeiro. Disponível em http://floradobrasil.jbrj.gov.br/2012/ FB000006 (acesso em 03-III-2012).

Costa, D.P. 2013a. Lophocoleaceae. In: Lista de Espécies da Flora do Brasil. Jardim Botânico do Rio de Janeiro. Disponível em http://floradobrasil.jbrj.gov.br/jabot/ floradobrasil/FB97265 (acesso em 16-XI-2013).

Costa, D.P. 2013b. Pilotrichaceae. In: Lista de Espécies da Flora do Brasil. Jardim Botânico do Rio de Janeiro. Disponível em http://floradobrasil.jbrj.gov.br/jabot/ floradobrasil/FB96686 (acesso em 16-XI-2013).

Costa, D.P. 2013c. Plagiochilaceae. In: Lista de Espécies da Flora do Brasil. Jardim Botânico do Rio de Janeiro. Disponível em http://floradobrasil.jbrj.gov.br/jabot/ floradobrasil/FB97749 (acesso em 16-XI-2013).

Costa, D.P. 2013d. Radulaceae. In: Lista de Espécies da Flora do Brasil. Jardim Botânico do Rio de Janeiro. Disponível em http://floradobrasil.jbrj.gov.br/jabot/ floradobrasil/FB97796(acesso em 16-XI-2013).

Costa, D.P. 2013e. Thuidiaceae. In: Lista de Espécies da Flora do Brasil. Jardim Botânico do Rio de Janeiro. Disponível em http://floradobrasil.jbrj.gov.br/jabot/ floradobrasil/FB97131 (acesso em 16-XI-2013).
Costa, D.P. 2014. Briófitas. In: Lista de Espécies da Flora do Brasil. Jardim Botânico do Rio de Janeiro. Disponível em http://reflora.jbrj.gov.br/jabot/ floradobrasil/FB128472. (acesso em 27-I-2014).

Costa, D.P. \& Bastos, C.J.P. 2013. Lejeuneaceae. In: Lista de Espécies da Flora do Brasil. Jardim Botânico do Rio de Janeiro. Disponível em http://floradobrasil. jbrj.gov.br/jabot/floradobrasil/FB97355 (acesso em 16-XI-2013).

Costa, D.P. \& Peralta, D.F. 2013a. Calymperaceae. In: Lista de Espécies da Flora do Brasil. Jardim Botânico do Rio de Janeiro. Disponível em http://floradobrasil. jbrj.gov.br/jabot/floradobrasil/FB96080 (acesso em 16-XI-2013).

Costa, D.P. \& Peralta, D.F. 2013b. Hypnaceae. In: Lista de Espécies da Flora do Brasil. Jardim Botânico do Rio de Janeiro. Disponível em http://floradobrasil.jbrj.gov.br/ jabot/floradobrasil/FB96448 (acesso em 16-XI-2013).

Costa, D.P. \& Peralta, D.F. 2013c. Leucomiaceae. In: Lista de Espécies da Flora do Brasil. Jardim Botânico do Rio de Janeiro. Disponível em http://floradobrasil. jbrj.gov.br/jabot/floradobrasil/FB96513 (acesso em 16-XI-2013).

Costa, D.P. \& Peralta, D.F. 2013d. Neckeraceae. In: Lista de Espécies da Flora do Brasil. Jardim Botânico do Rio de Janeiro. Disponível em http://floradobrasil. jbrj.gov.br/jabot/floradobrasil/FB96580 (acesso em 16-XI-2013).

Costa, D.P. \& Peralta, D.F. 2013e. Stereophyllaceae. In: Lista de Espécies da Flora do Brasil. Jardim Botânico do Rio de Janeiro. Disponível em http://floradobrasil. jbrj.gov.br/jabot/floradobrasil/FB97123 (acesso em 16-XI-2013).

Costa, D.P., Imbassahy, C.A.A., Silva, V.P.A.V. \& Monteiro, M.D. 2007. Banco de Dados -Briófitas do Estado do Rio de Janeiro. Disponível em http://www. jbrj.gov.br/pesquisa/div_tax/briofitas/bancodedados. htm (acesso em 03-XII-2012).

Crandall-Stotler, B., Stotler, R.E. \& Long, D.G. 2009. Morphology and classification of the Marchantiophyta In: A.J. Shaw \& B. Goffinet (eds.). Bryophyte Biology. 2 ed. University Press Cambridge, Cambridge, pp. 1-54.

Fearnside, P.M. 2001. Environmental impacts of Brazil's Tucuruí Dam: Unlearned lessons for hydroelectric development in Amazonia. Environmental Management 27: 377-396.

Fisch, G., Januário, M. \& Senna. R.C. 1990. Impacto Ecológico de Tucuruí (PA): Climatologia. Acta Amazonica 20: 49-60.

Goffinet, B.; Buck, W.R. \& Shaw, A.J. 2009. Morphology, anatomy, and classification of the Bryophyta. In: A.J.Shaw, \& B. Goffinet, Bryophyte Biology. 2 ed. University Press Cambridge, Cambridge, pp. 55-138.

Gradstein, S.R. 1995. Bryophyte Diversity of the Tropical Rainforest. Archives de Sciences de Genève 48: 91-96. 
Gradstein, S.R. \& Costa, D.P. 2003. Liverworts and Hornworts of Brazil. Memoirs of the New York Botanical Garden 88: 1-673.

Gradstein, S.R. \& Ilkiu-Borges, A.L. 2009. Guide to the Plants of Central French Guiana. Part 4. Liverworts and Hornworts. Memoirs of the New York Botanical Garden 76: 1-140.

Gradstein, S.R. \& Raeymaekers G. 2000. Tropical America (incl. México). In: T. Hallingbäck, \& N. Hodgetts. (compilers). Mosses, Liverworts and Hornworts. Status Survey and Conservation Action Plan for Bryophytes. IUCN/SCC Bryophyte Specialists Group. IUCN, Gland, Switzerland and Cambridge, UK., pp. 38-44.

Gradstein, S.R., Churchill, S.P. \& Salazar-Allen, N. 2001. Guide to the Bryophytes of Tropical America. Memoirs of the New York Botanical Garden 86: 1-577.

Hallingbäck, T. \& Hodgetts, N. 2000. Mosses, Liverworts and Hornworts. Status Survey and Conservation Action Plan for Bryophytes. IUCN/SCC Bryophyte Specialists Group. IUCN, Gland, Switzerland and Cambridge, UK.

Henriques, L.M.P. 2007. Aves. In: Avaliação e Monitoramento das Comunidades de Vertebrados na Área de Influência do Reservatório da UHE Tucuruí. Relatório Ano II, Belém. pp. 1-69.

Ilkiu-Borges, A.L. \& Lisboa, R.C.L. 2002a. Lejeuneaceae (Hepaticae). In: Lisboa, P.L.B. (org.). Caxiuanã: Populações Tradicionais, Meio Físico e Diversidade Biológica. Museu Paraense Emílio Goeldi, Belém, pp. 399-419.

Ilkiu-Borges, A.L. \& Lisboa, R.C.L. 2002b. Os Gêneros Leptolejeunea e Raphidolejeunea (Lejeuneaceae) na Estação Científica Ferreira Penna, Pará, Brasil. Acta Amazonica 32: 205-215.

Ilkiu-Borges, A.L. \& Lisboa, R.C.L. 2002c. Os Gêneros Lejeunea e Microlejeunea (Lejeuneaceae) na Estação Científica Ferreira Penna, Estado do Pará, Brasil e Novas Ocorrências. Acta Amazonica 32: 541-553.

Ilkiu-Borges, A.L. \& Lisboa, R.C.L. 2004. Os gêneros Cyclolejeunea, Haplolejeunea, Harpalejeunea, Lepidolejeunea e Rectolejeunea (Lejeuneaceae, Hepaticae) na Estação Científica Ferreira Penna, Pará, Brasil. Acta Botanica Brasilica 18: 537-553.

Ilkiu-Borges, A.L., Tavares, A.C.C. \& Lisboa, R.C.L. 2004. Briófitas da Ilha de Germoplasma, reservatório de Tucuruí, Pará, Brasil. Acta Botanica Brasilica, 18: 689-692.

Ilkiu-Borges , A.L., Macedo, L.P.C., Pereira, M.A.V. \& Lisboa, R.C.L. 2013. Briófitas em Caxiuanã: resultados do levantamento em duas parcelas da grade do PPBIO. In: P.L.B. Lisboa. (org.). Caxiuanã: paraíso ainda preservado. Museu Paraense Emílio Goeldi, pp. 247-256.
Kovach, W.L. 2011. MultivariateStatisticalPackage. Versão 3.0. Kovach Computing Services, Anglesey, Wales. Disponível em http://www.kovcomp.co.uk/mvsp/ downl.html(acesso em 09.12.2011).

Leão, N.V., Vieira, I.C.G. \& Ohashi, S.T. 2005. Levantamento florestal para implantação da reserva "in situ” na Ilha de Germoplasma - Tucuruí. Relatório do programa de revitalização do Banco de Germoplasma da Usina Hidroelétrica de Tucuruí, Pará.

Lisboa, R.C.L. \& Ilkiu-Borges, A.L. 1995. Diversidade das Briófitas de Belém (PA) e seu Potencial como Indicadoras de Poluição Urbana. Boletim do Museu Paraense Emílio Goeldi, Série Botânica. 11: 199-225.

Lisboa, R.C.L. \& Ilkiu-Borges, F. 1996. Florística das Briófitas da Serra dos Carajás e sua possível utilização como indicadoras de metais. Boletim Museu Paraense Emílio Goeldi, Série. Botânica, Belém, 12: 161-181.

Lisboa, R.C.L. \& Ilkiu-Borges, A.L. 2007. Uma Nova Avaliação da Brioflora da Reserva Mocambo, Belém (PA). In: J.I. Gomes, M.B. Martins, R.C.V. Martins-DaSilva, S.S. Almeida (Orgs.). Diversidade e Dinâmica da Área de Pesquisa Ecológica do Guamá-APEG. Embrapa Amazônia Ocidental, Belém, pp. 149-174.

Lisboa, R.C.L \& Santos, R.C. 2005a. Helicophyllaceae (Bjryophyta), Nova Ocorrência para o Estado do Pará, Brasil. Acta Amazonica 35: 343-346.

Lisboa, R.C.L \& Santos, R.C. 2005b. Ocorrência do Gênero Papillaria (Müll. Hal.) Müll. Hal. (Meteoriaceae, Bryophyta) na Amazônia. Boletim do Museu Paraense Emílio Goeldi, Série Ciências Naturais 1: 61-63.

Moraes, E.N.R. \& Lisboa, R.C.L. 2006. Musgos (Bryophyta) da Serra dos Carajás, Estado do Pará, Brasil. Boletim do Museu Paraense Emílio Goeldi, Ciências Naturais 1: 39-68.

Moraes, E. de N.R. \& Lisboa, R.C.L. 2009. Diversidade, taxonomia e distribuição por Estados brasileiros das famílias Bartramiaceae, Brachytheciaceae, Bryaceae, Calymperaceae, Fissidentaceae, Hypnaceae e Leucobryaceae (Bryophyta) da Estação Científica Ferreira Penna, Caxiuanã, Pará, Brasil. Acta Amazonica 39: 773-792.

Moura, O.S. de, Ilkiu-Borges, A.L. \& ReinerDrehwald, M.E. 2012. A new species of Lejeunea Lib. (Lejeuneaceae) from Low Várzea forest in lower Amazon (Pará, Brazil). Nova Hedwigia 95: 197-202.

Peralta, D.F. 2013. Frullaniaceae. In: Lista de Espécies da Flora do Brasil. Jardim Botânico do Rio de Janeiro. Disponível em http://floradobrasil.jbrj.gov.br/jabot/ floradobrasil/FB97311 (acesso em 16-XI- 2013).

Peralta, D.F \& Yano, O. 2011. Bryophytes from the Museu de Biologia Mello Leitão Herbarium, Espírito Santo, Brazil. Boletim do Instituto de Botânica 21: 47-80.

Pires, J.M. 1973. Tipos de vegetação da Amazônia. Publicações Avulsas Museu Goeldi, Belém. 20: 179-202. 
Pires, J.M. 1976. Aspectos ecológicos da floresta amazônica. In: Anais do II Congresso Brasileiro de Florestas Tropicais, Mossoró, RN, Sociedade Brasileira de Engenheiros Florestais, pp. 235-287.

Pires, J.M. \& Prance, G.T. 1977. The Amazon forest: a heritage to be preserved. In: G. T. Prance (ed.). Extinction in forever. The New York Botanical Garden, pp. 183-220.

Pires, J.M. \& Salomão, R. P. 2007. Histórico científico, institucional e perspectivas atuais da área de pesquisa Ecológica do Guamá - APEG, da Embrapa Amazônia Oriental, Belém, Pará. In: J.I. Gomes, M.B. Martins, R.C.V. Martins-Da-Silva, S.S. Almeida (orgs.). Diversidade e Dinâmica da Área de Pesquisa Ecológica do Guamá-Apeg. Embrapa Amazônia Ocidental, Belém, pp. 28-39.

Richards, P.W. 1984. The Ecology of tropical forest bryophytes. In: R. M. Schuster (ed.). New Manual of Bryology. Hattori Botanical Laboratory v.2. pp. 1233-1270.

Sanches, F. \& Fisch, G. 2005. As possíveis alterações microclimáticas devido a formação do lago artificial da hidrelétrica de Tucuruí - PA. Acta Amazonica 35: 41-50.

Santos, N.D. \& Costa, D.P. 2010. Phytogeography of the liverwort flora of the Atlantic Forest of southeastern Brazil. Journal of Bryology 32: 9-22.

Santos, N. D., Costa, D.P., Kinoshita, L.S. \& Shepherd, G.J. 2011. Aspectos brioflorísticos e fitogeográficos de duas formações costeiras de Floresta Atlântica da Serra do Mar, Ubatuba/SP, Brasil. Biota Neotropica 11: 425-438.

Santos, R.C. \& Lisboa, R.C.L. 2003. Contribuição ao Estudo dos Musgos (Bryophyta) no Nordeste Paraense, Zona Bragantina, Microrregião do Salgado e Município de Viseu, Pará. Acta Amazonica 33: 415-422.

Santos, R.C. \& Lisboa, R.C.L. 2008. Musgos (Bryophyta) da Microrregião do Salgado Paraense e sua Utilização como Possíveis Indicadores de Ambientes Perturbados. Rodriguésia 59: 361-368.

Schilling, A.C.\& Batista J.L.F. 2008. Curva de acumulação de espécies e suficiência amostral em florestas tropicais. Revista Brasileira de Botânica 31: 179-187.

Schuster, R.M. 1983. Phytogeography of bryophytes. In: R. M. Schuster (ed.). New Manual of Bryophtes. Hattori Botanical Laboratory, pp. 463-626.

SEMA. 2012. Secretaria de Estado de Meio Ambiente. Unidades de Conservação Federais, Estaduais e Municipais do Estado do Pará. Disponível em http://www. sema.pa.gov.br/interna.php?idconteudocoluna $=4625$ (acesso em 28-I-2012).
Shaw, A.J., Szövényi, P. \& Shaw, B. 2011. Bryophyte diversity and evolution: windows into the early evolution of land plants. American Journal of Botany 98: 352-369.

Souza, A.P.S. \& Lisboa, R.C.L. 2005. Musgos (Bryophyta) na Ilha Trambioca, Barcarena, PA, Brasil. Acta Botanica Brasilica 19: 487-492.

Souza, A.P.S. \& Lisboa, R.C.L. 2006. Aspectos Florísticos e Taxonômicos dos Musgos do Município de Barcarena, Pará. Boletim do Museu Paraense Emílio Goeldi, Ciências Naturais 1: 81-104.

Tavares, A.C.C. 2004. Lejeuneaceae (Marchantiophyta) do Reservatório da Hidrelétrica de Tucuruí, Pará, Brasil. Dissertação de Mestrado, Universidade Federal Rural da Amazônia, Belém.

Tavares, A.C.C., Lisboa, R. C. \& Ilkiu-Borges, A.L. 2006. Novas Ocorrências de Lejeuneaceae (Hepaticae) para o Estado do Pará, Brasil. Boletim do Instituto de Botânica 18: 173-179.

Vanzolini, P.E. 1992. Paleoclimas e Especiação em Animais da América do Sul Tropical. Estudos Avançados 6: 1-25.

Vieira, I.C.G, Toledo, P.M, Silva, J.M.C. \& Higuchi, H. 2008. Desforestation and threats to the biodiversity of Amazonia. Brazil. Journal Biology 68: 631-637.

Yano, O. 1981. A checklist of Brazilian mosses. Hattori Botanical Laboratory 50: 279-456.

Yano, O. 1984a. Briófitas. In: O. Fidalgo \& V.L.R.Bononi (eds.). Técnicas de coleta, preservação e herborização de material botânico. Série Documentos. Instituto de Botânica, São Paulo, pp. 27-30.

Yano, O. 1984b. Checklist of Brazilian liverworts and hornworts. The Journal of the 56: 481-548.

Yano, O. 1989. An additional checklist of Brazilian bryophytes. The Journal of the Hattori Botanical Laboratory 66: 371-434.

Yano, O. 1995. A new additional annotated checklist of brazilian bryophytes. The Journal of the Hattori Botanical Laboratory 78: 137-182.

Yano, O. 2006. Novas adições às briófitas brasileiras. Boletim do Instituto de Botânica 18: 229-233.

Yano, O. 2008. Catálogo de Antóceros e Hepáticas Brasileiros: literatura original, basiônimo, localidadetipo e distribuição geográfica. Boletim do Instituto de Botânica 19: 1-110.

Yano, O. 2011a. Catálogo de Musgos Brasileiros: Literatura Original, Basiônimo, Localidade-tipo e Distribuição Geográfica. Instituto de Botânica, São Paulo.

Yano, O. 2011b. New records of bryophytes for the States of Brazil. Boletim do Instituto de Botânica 21: 19-45.

Yano, O. \& Peralta, D.F. 2011. Bryophytes from the Serra de São José, Tiradentes, Minas Gerais State, Brazil. Boletim do Instituto de Botânica 21: 141-172. 